Received: 16.09.2014.

Professional article

UDK: [371.3:81'367.33]:004

\title{
ATTRIBUTE AND APPOSITIONAL SENTENCE: TRADITIONALAND ELECTRONIC
}

MSc Snežana Laketa, master of IT, professor

Primary school Vuk Karadžić, Vlasenica, Republic of Srpska

snezanalaketa9@gmail.com

Jovanka Vlačić, professor of Serbian language and literature

Primary school Vuk Karadžić, Vlasenica, Republic of Srpska

jokevlacic@gmail.com

\section{SUMMARY}

This paper aims to show that the same or similar teaching programs can be expressed through two different approaches: the traditional and E-learning.

Lesson Attribute and appositional sentence is processed in two ways: traditional and electronic. Traditional approach is going to be implemented during the first lesson. The second approach, will be implemented through revision of the teaching unit. Electronic access is possible because the school has been equipped computers by the project Dositej. The project Dositej that has a goal of promoting interactive learning using ICT. Electronic access has proven to be dynamic. The combination of these two approache (traditional and electronic) has proved fruitful and interesting to students.

Key words: traditional teaching, E-learning.

\section{INTRODUCTION}

Within the project Dositej 1: 1, our school is equipped with 7 electronic classrooms so that each student possesses a laptop. The project Dositej is promoting interactive learning using ICT and investing in the skills of the 21st century. It involves the delivery of computers for students and teachers, all necessary hardware and software, and appropriate training and support. Project is supported by the Ministry of the Education and Culture of the Republic of Srpska and LANACO company.

Among many other sectors that the LANACO Company is consisted of, its educational sector that organizes courses, seminars, workshops and presentations on IT and related topics is of the most importance to our agenda. Their innovative approach to teaching and working with the latest programs and equipment together with many satisfied clients has made them a regional leader in IT training.

Their ability to improve and to incorporate new technological advances has made them able to build a team that provides professional development to their clients. More than twenty experienced and qualified coaches work on generously transferring their knowledge to their trainees thus helping them to achieve their professional or personal goals. Portfolio of educational content and programs offered includes:

- Microsoft training,

- Oracle training,

- ECDL training,

- Business skills workshops,

- Specialised courses, 
- Holiday workshops,

- Summer internships for students,

- CertiPort exams, - preparing for and taking exams,

- And many other types of training...

All training courses are conducted on a "one on one" basis, meaning that one computer is assigned to one student. Aside from the regular in class training, the company has been doing online training in the past few years. In order to manage online training the company has made its own system - ELMs (Electronic Learning Management System). LANACO is also engaged in making electronic courses and tests for their clients and employees likewise.

\section{PROGRAMS USED FOR ELECTRONIC TEACHING}

The "Dositej project - 1:1 eLearning in primary schools in the Republic of Srpska" is a project that has a goal of promoting interactive learning using ICT. Ministry of education and culture of Republic Srpska aims to equip all students in all primary schools in the Republic of Srpska with netbook computers (Intel based Classmate PCs), as well as all teachers with laptop computers, and servers, networking and communications equipment.

During the first phase of the project, in the 2012, 65 primary schools were included in the project. Schools received equipment and computers for use in the classrooms and laptops for teachers. 408 e-classrooms were prepared and 10,200 computers for students were delivered (with integrated software for classroom collaboration - Mythware solution).

This way of organising E-learning gives us the opportunity to use different types of resources in order to improve quality of the teaching process. Word, Power Point, Web Quest are some of the programs we use taking into account the ISTA standards (Laketa, 2014). For more detail on quality standards in teaching you can visit the online magazine Dositej: http://casopisdositej.eucionica.com/index.php/item/129-standardikvalitetaunastavi .

Word is a program whose options are of great importance for e-learning. It allows the realization of different models of teaching hours and it can be used in all subject areas. You can find various lesson plans that demonstrate the usage of Word in teaching in the online magazine Dositej (Vlacic, 2014): http://casopisdositej. eucionica.com/index.php/item/134-pripremabezlicnerecenice http://casopisdositej.eucionica.com/images/casopisBroj3/dositejBroj3.pdf .

Power Point is a program that is highly exploited in teaching due to its simplicity and appropriateness. One of its many advantages is that we can involve students in the direct implementation of the thematic areas. You can find various lesson plans that demonstrate the usage of Power Point in teaching in the online magazine Dositej http://casopis dositej.eucionica.com/images/casopisBroj2/dositejBroj2.pdf

http://casopisdositej.eucionica.com/images/casopisBroj1/dositejBroj1.pdf

The WebQuest as an efficient methodology which boosts development of critical thinking even in primary schools` grades and force learners to link school knowledge with real world experience. It is written in such a manner that teachers with poorer IT skills can also grasp it and get some ideas for refreshing their teaching. An example is given through the WebQuest: "The most significant events during the last year - Floods in $\mathrm{BiH}$ " as a unit used in homeroom classes for seventh graders of elementary school. http://casopisdositej.eucionica.com/ index.php/item/130-integracijinternetaunastavi 


\title{
THE TRADITIONAL APPROACH TO TEACHING UNIT ATTRIBUTE AND APPOSITIONAL SENTENCES
}

\author{
Basic data: \\ Class VIII; \\ Running Time: 45 minutes; \\ Operational data: \\ Program/ course content "Attribute and appositional sentence" \\ Type of lesson: processing new material \\ Curriculum forms: individual, frontal form of work \\ Teaching methods: dialogue, monologue, demonstrative method. \\ Objectives of the lesson:
}

Educational/ cognitive: A review of the concept of sentences with all its constituents. Developing the ability to understanding of the lesson by repeating all generally related to the notion of the sentence and its types.

Educational: Activate students' cognitive activity and creativity, and gradually develop their analytical and synthetic thinking through the experience of the beauty of language values. Enable students to self-guidance through examples of the need to develop new knowledge and creation.

Functional/practical: To enable students to understand the value and proper use of language. Interested students to independently search for linguistic problems through the teaching unit that we process. To develop in students a love of grammar and explain to them what is its significance.

Lesson

The introductory part of the lesson: We are starting to learn, depending on complex sentences. Our story unfolded from an overall idea depending on complex sentences through each individual species. On today's lesson we will learn another type of subordinate clauses, such as adjective clauses. Students write a letter to the board: "attribute and appositional sentence." As I said, today we are going to teach adjective clauses, and the next moment we speak of appositional phrases. Subdivided types of sentences in special classes to help you understand how to avoid the confusion of these types of sentences. Before we show the examples of what these adjective clauses we have to repeat what these attributes. I'm writing a subtitle: "adjective clauses."

\section{What are Attributes?}

Attributes are namespace additions regardless of rečeničkoj function of the noun was used, the addition of which it refers may be. Attributes are expressed adjectives, adjectival pronouns and case forms of nouns with the proposal or not, ie. prepositional-padežna structures. Attributes express a characteristic idea signified the noun to which this attribute is. They further define the nouns they qualify and are therefore not separated by a comma.

The main part of the class ( 35 minutes): We'll write a sad three sentences in which we will highlight a member. Your job is to notice that it is a member.

On Stražilovo we climbed a steep trail.

On Stražilovo we climbed a steep trail.

On Stražilovo we climbed the trail which was very steep.

In these sentences are prominent members of the service attributes. Attribute is expressed in a single sentence in a word, a sentence is expressed phrase (dependent adjective phrase) in the third sentence is expressed in the entire sentence / dependent adjective clauses.

Write to:

Adjective clause is a dependent clause that functions as an attribute to the noun or noun pronoun to which it refers. Adjective clauses are never separated by a comma nor attribute. The following sentence expanding with several types of attribute sentences: 
Milos has a dog: - that is dangerous

- Which bites

- Which I can not approach

- That the attacks.

Write the following sentence: We pass the two huge oak trees that were old but for Tolstoy's life, entered the birch forests he planted his hand.

What add-ons in this sentence are nouns oak and forest?

Two oak trees - huge.

Who were old for Tolstoy's time.

Forest - birch.

He has his hand planted.

What show these supplements?

These amendments show that the namespace and to further define the nouns they qualify. Write the following complex sentence and divide it into simple sentences:

We started the trail / that he liked to go/ and we will forever awake maintain our fans / which each come in Yasnaya Polyana. I

How many in this complex sentence has attribute sentences and conjunctions which are related to nouns provide a closer?

This sentence has three adjective clauses that are introduced conjunctions: that, that, that.

The above sentence could be written like this: Path as it liked to go.

What will the eternal waking maintain his devotees each day coming in Yasnaya Polyana.

It could be like this: Path - he liked to go.

- That will forever keep waking his devotees who come every day to Yasnaya Polyana.

From this we can conclude that the most common conjunctions attribute sentence relative pronouns who and what, and that they are often interchangeable, and the meaning will remain the same. When we have a word in the function of conjunctions that can perform a function in the sentence (such as. Pronoun) then call them linker funds because they are not pure conjunctions. Conjunctions attribute sentences are relative pronouns who, which, whose, what, how and where contributions as and when.

After sightseeing museums we went into the woods where Tolstoy often walked. - (Adjective clauses)

Day / when Janko was born / all family members are remembered all his life. /

At a time when major decisions are made so no need to think about the situation.

We see that the linker where introduce adjective clauses that have local significance as a conjunction. Linker when introducing the adjective clauses with time meaning. Conjunctions where and when we can change the linker.

Conclusion: Adjective clauses did not merely introduce the relative pronoun that, but what pronouns whose, what and how and why are all adjective clauses, relative clauses. Because they are in a complex sentence always refer to a noun that further define (Kovacevic, 2008).

\title{
ELECTRONIC ACCESS TO IMPLEMENTATION OF TEACHING UNITS "ATTRIBUTE AND APPOSITIONAL SENTENCES"
}

\author{
Basic data: \\ Class VIII; \\ Running Time: 45 minutes; \\ Operational data: \\ Programming / teaching content "Attribute and appositional sentence" \\ Type of lessons: repetition \\ Objectives of the lesson:
}


Educational/ cognitive: A review of the concept of sentences with all its constituents. Developing the ability to understanding of the lesson by repeating all generally related to the notion of the sentence and its types.

Educational: Activate students' cognitive activity and creativity, and gradually develop their analytical and synthetic thinking through the experience of the beauty of language values. Enable students to self-guidance through examples of the need to develop new knowledge and creation.

Functional/ practical: To enable students to understand the value and proper use of language. Interested students to independently search for linguistic problems through the teaching unit that we process. To develop in students a love of grammar and explain to them what is its significance.

Lesson: The introductory part of the lesson (5 minutes) Today our topic is appositional sentence. Before we start talking about this kind of subordinate clauses shall repeat what they are namespace-ons. Namespace attribute as accessories and apposition. Attribute is the addition of books, and he says its a feature. Not be separated by a comma from the nouns they qualify. Can be expressed adjectives or adjectival pronouns. Apposition of the directory supplement that explains the noun or pronoun with a directory that is. She reported only a noun or noun phrase always comes after the noun it explains to her is necessarily agree in case and number, and mostly in the genus. Always separates.

At the last moment, we explained how to introduce attribute dependent clauses, and at this point we apply the same process to appositional sentence, but with the use of e-learning. Students receive their tasks through programs Mythware eUcionica. Teacher their forwards Word document that can be read and it started to complete the sentences. The teacher can follow any responses to your server, to provide additional explanations.

Task 1. Apposition turn into dependent appositional sentence.

Tolstoi great Russian writer and nobleman lived very modestly.

Tolstoy, who is a Russian writer and nobleman.

Appositional subordinate clause (inset).

Task 2. Refer the following statement to get the correct statements:

Appositional sentence she sentence in a complex sentence has the function and meaning of apposition. Appositional sentence, and apposition, always separated by a comma, and on both sides if it is inserted.

It's not always easy to distinguish between the attribute and appositional phrases. In this differentiating major role we play the meaning of the sentence.

Task 3. Looking at the following sentences determine whether attribute or apozicijskih sentences in them, they all want to hang out with a boy/ who is the best student in the school./ In this sentence we have the adjective clauses because we see that it performs in this complex sentence, function attributes, because if we was omitted from this complex sentences we do not know about what the boy in question and would not have the full meaning.

Marko later still he stops at the place/ where he was educated. /In this sentence we have an independent adjective clauses. That is left out we do not know about where you place it.

In the year/ when was the biggest drought / brother went abroad./ This attribute subordinate clause.

Problem 4. Consider the following sentences and determine what it is:

We all want to hang out with Mark/ who is the best student in the school. /

Marko later still He visited Belgrade / where he was educated. /

The year before / when was the biggest drought / brother went abroad. /

In these three examples we have mentioned appositional sentence. Apparently it is not easy to distinguish from the attribute, but if this group of sentences omit appositional phrases from the complex, we will again convey clear information as apposition is another name that more closely defines the noun.

Task 5. Have you ever noticed how a complex sentence introduced attribute and appositional phrases (which connectors)? 
Attribute and appositional sentences into a complex sentence introducing the same connectors (relative pronouns and sometimes supplements) and it is still one of the difficulties in the process of their differentiation.

Task 6. Attribute and appositional sentence essentially differ only in the relevant sense. Explain it in your own words:

1) Adjective clauses

They are always determined more accurately vague notion directory (without them we would not know what that that term means); only when the state adjective clauses, noun to which the sentence refers to a full and true meaning. Adjective clauses accurately determined, narrowing the meaning of the noun to which they refer. They actually specify its (noun) meaning. They are always tato certain relative clauses.

2) Sentences appositional

Always added some new information about the nouns that the apposition determined. These sentences make later some information about the specified term given to the noun with which the apposition stands. Accordingly, the appositional sentence may be omitted from the complex, and that the meaning does not change. Therefore, the appositional additional sentences of the respective sentences.

\section{CONCLUSION}

Through this example, we have shown how important it is to pay attention to innovation in teaching. Lesson Attribute and appositional sentence is processed in two ways: traditional and electronic. The traditional approach has shown the quality of presentation of what students must take as a basis to be able to decompose through e-learning. Electronic access is possible because the school has been equipped by the project Dositej. The Dositej project - 1:1 eLearning in primary schools in the Republic of Srpska is a project that has a goal of promoting interactive learning using ICT. Electronic access has proven to be dynamic because the students in addition to repeating knowledge further complement hour exploring the teaching unit in a different way.

Results show that in practice, depending on the lessons the teacher should select whether to present your a traditional teaching or of electronics or a combination of both. Lesson Attribute and appositional sentence is processed in two ways: traditional and electronic. The combination of these two approaches has proved fruitful and interesting to students and must be applied more frequently combined.

\section{REFERENCES}

1.) Kovacevic, Milos (2008): Serbian language and culture expression for the 8th grade, East Sarajevo: Institute for textbooks and teaching aids.

2.) Laketa, Snezana (2014): Quality standards in teaching, Dositej 3, accessed 09/07/2014. With link http://casopisdositej.eucionica.com/index.php/item/129standardikvalitetaunastavi

3.) Vlacic, Jovanka (2014): Preparation - Impersonal sentences, Dositej 3, accessed 09/07/2014. with link http://casopisdositej.eucionica.com/index.php/item/134pripremabezlicnerecenice 